\title{
A história como pesadelo: a representação alegórica da Argentina peronista no romance El examen (1950) de Julio Cortázar
}

\author{
History as nightmare: the allegorical representation of Peronist Argentina in the novel \\ El examen (1950) by Julio Cortázar
}

Rafael Vaz de Souza

Doutorando em História Social pela Universidade de São Paulo rafael.vaz.souza@hotmail.com

\begin{abstract}
Resumo: Entre os anos 1945 e 1955, os argentinos viveram sob o governo de Juan Domingo Perón, período que ficaria conhecido como a "Década Peronista". Nesta, práticas autoritárias e demagógicas conviveram com significativas mudanças na estrutura política do país, sendo a participação das massas populares nos comícios organizados pela máquina estatal o seu maior símbolo. Neste artigo, procuraremos ver como a literatura argentina, majoritariamente um produto das classes médias de Buenos Aires contrárias ao governo, internalizou os debates de sua época e construiu uma representação própria do regime peronista. Para isto, analisaremos o romance El examen (1950), de Julio Cortázar, de escrita contemporânea ao fervor dos anos peronistas e que os representa de maneira alegórica e sob o signo do pesadelo.
\end{abstract}

Palavras-chave: Julio Cortázar, literatura argentina, peronismo.

\begin{abstract}
Between 1945 and 1955, Argentinians lived under the rule of Juan Domingo Perón, in a period that would be known as "The Peronist Decade". In this, authoritarian and demagogic practices were together with substantial changes in Argentina's political structure, symbolized in the massive participation in the political rallies orchestrated by the State machinery. In this article, we aim to see how Argentinian literature, mainly a product of Buenos Aires middle classes, most of them in the opposition to the government, has internalized the debates of its time and has created a unique representation of the Peronist regime. Thus, we aim to analyze the novel El examen (1950), written by Julio Cortázar during the years of the Peronist government, which are allegorized by its text under the sign of nightmare.
\end{abstract}

Keywords: Julio Cortázar, Argentinian literature, Peronism. 
Escrito originalmente no ano de 1950, o primeiro romance ao qual temos acesso do então jovem e desconhecido Julio Cortázar, El examen, apenas veio a público em 1986, 36 anos depois de ser finalizado e em meio à onda de publicações póstumas desencadeada pela morte do autor dois anos antes. Prevendo o interesse que a sua morte produziria no público e na crítica por textos desconhecidos e anteriores a Bestiario, Cortázar, no início da década de 80 , revisa e prepara o romance para ser publicado, e agrega uma Nota Introdutória que postula, já na primeira página do livro, uma chave de leitura do texto sob o signo da alegoria política. ${ }^{1}$

Contemporâneo a uma Argentina que vivia o auge do regime peronista, o romance nos apresenta aos personagens Andrés, Juan, Clara, Stella e o cronista na véspera de uma importante prova a ser realizada em la Casa, espécie de instituição voltada ao ensino superior, e à qual alguns deles devem comparecer. Ao longo da narrativa, o leitor acompanha as andanças dos protagonistas pela cidade de Buenos Aires, assim como suas impressões e extensos diálogos sobre arte, filosofia, história e a atual situação, política e cultural, do país. Ademais, há a misteriosa e fantástica presença de uma estranha neblina, responsável pela proliferação de fungos que irão progressivamente corroer a capital, levando-a a iminência de sua total destruição ao final do romance.

\section{1) O comício: Perón, Eva e o culto apaixonado pelos símbolos peronistas}

Como dito anteriormente, El examen é um texto alegórico e sua primeira alusão mais explícita ao peronismo e seus personagens se dá no episódio em que os protagonistas resolvem, por insistência de Stella, visitar a celebração realizada pelo governo na Plaza de Mayo. ${ }^{2}$ De início, eles mal sabem o que o evento significa, o que mostra o seu inicial desinteresse pela política do seu próprio país, e avançam pela multidão que apinha a totalidade da praça, “en un confuso crecer de cuerpos y nucas y pañuelos al cuello”, até

\footnotetext{
${ }^{1}$ Na Nota, Cortázar afirma ter escrito o livro "en una Buenos Aires donde la imaginación poco tenía que agregar a la historia para obtener los resultados que verá el lector" (CORTÁZAR, 1987: 13). De história milenar e complexa, o termo alegoria será tomado por nós em sua acepção clássica, ou seja, romântica, que tem em Goethe sua formulação mais acabada. Ver a seguinte citação: "Há uma grande diferença entre o poeta que busca o particular a partir do geral e o que contempla o geral no particular. Do primeiro procedimento surge a alegoria, na qual o particular só serve como instância ou exemplo do geral; o segundo, por sua vez, é a verdadeira natureza da poesia: a expressão do particular sem nenhuma referência ao geral" (AVELAR, 2003: 15). Segundo esta acepção, o texto alegórico é, grosso modo, aquele que aborda uma situação geral - o contexto sócio-político do regime peronista, para usarmos nosso exemplo - a partir de uma situação particular, mas de maneira alusiva e oblíqua, ou seja, sem que se explicite a conexão interna responsável por reger a identificação de uma com a outra.

${ }^{2}$ Cabe ressaltar o caráter alusivo do texto, típico da alegoria, no qual não há, em nenhum momento, qualquer menção mais explícita aos nomes de Perón, Eva ou ao termo "peronismo".
} 
que chegam numa clareira onde encontram uma "mujer vestida de blanco, una túnica entre delantal de maestra y alegoría de la patria nunca pisoteada por ningún tirano, el pelo muy rubio desmelenado cayéndole entre los senos" (CORTÁZAR, 1987: 62).

A não ser pelo estado desgrenhado do cabelo da mulher, poderíamos tomá-la como uma espécie de representação de Eva Perón, líder central do movimento ao lado de seu marido e um dos maiores ícones da ideologia peronista. Como podemos ver na passagem, seu vestido branco, cuja cor imaculada representa a imagem da pátria nunca pisoteada pelas botas da tirania, evoca também a ideia de uma possível pureza de espírito da mulher que o veste, além de recordar a figura da professora bondosa, responsável por instruir e acalentar o povo. Esses três significados aparecem de certa forma reforçados na cantilena iniciada por um de seus acompanhantes:

-Ella es buena - dijo - Ella es muy buena.

-Ella es buena - repitieron los otros.

-Ella viene de Lincoln, de Curuzú Cuatiá y de Presidente Roca - dijo el hombre.

-Ella viene - repitieron los otros.

-Ella viene de Formosa, de Covunco, de Nogoyá y de Chapadmalal.

-Ella viene.

-Ella es buena - dijo el hombre.

-Ella es buena

(CORTÁZAR, 1987: 62-3)

Assim, temos a constante reiteração da bondade de uma mulher que, transformada em uma entidade feminina sem nome, aparece como vinda das mais diversas regiões do país. Essa transformação simbólica é semelhante à ocorrida com Evita, que abandona sua inicial irrelevância política quando da campanha presidencial de Perón para, mediante o sucesso das ações assistencialistas de sua Fundación Eva Perón, se transformar na "benfeitora do povo". ${ }^{3}$ Para Beatriz Sarlo, o desenvolvimento de uma espécie de culto do povo por Evita foi fruto não apenas da relação pessoal por ela desempenhada para com seus descamisados, mas também pela exaustiva reiteração, mediante a propaganda oficial, dessas ações: como a mulher da cantilena, os atos de Evita representavam e

\footnotetext{
${ }^{3}$ Mariano Ben Plotkin conta que, apesar do protagonismo posterior que a propaganda peronista lhe outorgará, o papel de Eva no desenrolar dos dias anteriores ao mitológico 17 de Outubro se manteve dentro dos limites do que se esperava de uma esposa dedicada: "Eva ocupaba el lugar que se esperaba de una mujer fiel a su hombre - el de la lealtad sin límites" (PLOTKIN, 2005: 972).
} 
alcançavam todos os cantos do país, seus esforços para o bem do povo eram incansáveis e sua bondade, infinita. ${ }^{4}$

O fascínio causado pela mulher é tanto que Clara, para quem a figura histérica daquela se apresenta, a priori, como um espetáculo grotesco, acaba sendo hipnotizada pelo ritual e também começa, "al final, murmurar con los otros: "Ella es buena"” (CORTÁZAR, 1987: 63). Por outro lado, a mulher, que passa a realizar movimentos convulsivos em certo momento da cena, representa também outro aspecto da figura de Evita, que, por sua retórica brutal e impiedosa para com os inimigos do regime, coloca em segundo plano a figura de "hada buena", de "dama de la esperanza", e assume cada vez mais o título, tão proclamado pela CGT, de "abanderada de los trabajadores" (HALPERÍN DONGHI, 1995: 161). Desta forma, elevada à categoria de entidade onipresente e combativa, a mulher da Plaza de Mayo - de modo análogo ao de Eva - se transforma, nas palavras de Sarlo, em um objeto fanático de paixão, possuidor de tamanha persuasão que acaba por subjugar, mesmo que momentaneamente, a individualidade opositora de Clara. ${ }^{5}$

Após a cena da mulher, Andrés instiga os demais a se afastar e, juntos, percorrem dentre a multidão até chegarem à base da Pirámide de Mayo, dentro da qual há a misteriosa exposição de uma relíquia que descobrem ser a verdadeira atração da celebração. Antes de entrarem, porém, os personagens devem esperar na fila e tem de ouvir a ladainha de um orador que, em cima de um palanque, realiza, de maneira incoerente e entrecortada, um discurso permeado por palavras de ordem, proclamações à Pátria e imprecações contra supostos inimigos. ${ }^{6}$ Se a mulher de branco pode ser tomada como uma representação da figura de Evita e seus movimentos, simulacros de sua retórica, o recém-aparecido orador pode ser entendido ele também como uma espécie de Perón em miniatura, cujo discurso reproduziria, ao menos em sua estrutura básica, os do

\footnotetext{
4 "As imagens de Eva abraçando, tocando, acariciando, apertando mãos, certificam (e continuaram a certificar depois da morte) sua qualidade de ponte, de médium, entre o regime e o povo. As imagens que a mostram no trabalho ou na tribuna [...] a apresentam como o lugar onde se ancoram materialmente o Estado de bem-estar e a política peronista" (SARLO, 2005: 93).

5 "O fanatismo abole essa dimensão da autoconsciência irônica. No caso do fanatismo (como no de outras paixões), as emoções, os sentimentos que pertenceriam ao universo cotidiano do sujeito são esmagados sob o domínio do sentimento único que chamamos paixão" (SARLO, 2005: 242).

6 "Como señala la historiadora francesa Mona Ozouf, mientras el legislador hace la ley para el pueblo, los rituales y los festivales políticos hacen al pueblo para la ley. Eso es así porque los rituales políticos cumplen una doble función. Por un lado crean una unidad simbólica entre los participantes que se reconocen a sí mismos como miembros de una comunidad política dada: partido, nación, patria. Pero por otro lado, en especial en regímenes de tipo autoritario [...], los rituales también cumplen una función de exclusión, privando de legitimidad a los contendientes políticos que no participan de los mismos" (PLOTKIN, 2005: 1115-1121).
} 
Presidente. Assim, tanto este quanto aquele se colocam em posição superior em relação aos seus interlocutores - seja esta a do palanque improvisado de um ou a do balcão da Casa Rosada de outro - e dirigem suas palavras para um povo em posição inferior, espacial e metaforicamente falando, cujas respostas acabam por ser sempre condicionadas pelo primeiro. ${ }^{7}$

Finalmente, a fila começa a andar, os personagens podem deixar o orador para trás e começam a adentrar na Pirámide, onde se deparam com um ritual bizarro de adoração a um osso. Como afirma na Nota que introduz o romance, Cortázar vê nesse episódio a prefiguração profética do culto ao corpo de Evita que se instaurará após sua morte. ${ }^{8}$ Depois de um significativo suspense sobre o que haveria dentro da tenda, quase não há descrição sobre a visita em si, sendo que ela logo acaba e dá lugar a mais um orador, o qual proclama a importância para a Pátria do contato realizado com a relíquia. Desta forma, tal episódio parece ser a culminação de um progressivo clima de irracionalidade geral, já presente nos movimentos alucinantes da mulher e na retórica confusa do orador, que se apodera do comício, aproximando-o a um estado de transe coletivo.

De maneira análoga, outra cena também fugaz, apesar de melhor detalhada, causa um efeito semelhante no leitor ao colocá-lo frente à mutilação de uma criança pelos participantes do comício. Estes, munidos de uma agulha de costura, perfuram o rosto de um menino enquanto, de maneira alucinada, repetem a palavra enemigo, numa representação escrachada da brutalidade incentivada pelo regime contra seus opositores e que remete, por sua violência e gratuidade, ao assassinato do judeu pelos personagens do conto "La fiesta del monstruo", de Borges e Bioy Casares. ${ }^{9}$

\footnotetext{
${ }^{7}$ Como nos mostra Ben Plotkin, desde o primeiro grande ato peronista, acontecido no próprio 17 de Outubro de 1945, o discurso que realiza Perón, recém-libertado pelas mobilizações populares, procura definir o lugar superior do líder frente ao povo que lhe escuta e prestigia: "Perón estaba fijando un lugar para cada uno de los protagonistas de ese 17 de Octubre: el suyo en el balcón de la Casa Rosada, y el del pueblo en la Plaza de Mayo. En otras palabras, Perón estaba tornando el evento en un espectáculo. [...] La clase obrera se había movilizado no solo para libertar a Perón, sino también para restaurarlo en el lugar que le pertenecía por derecho propio: el balcón de la Casa de Gobierno" (PLOTKIN, 2005: 777-783).

8 "Más adelante y desde muy lejos supe que esos mismos amigos habían creído ver en ciertos episodios una premonición de acontecimientos que ilustraron nuestros anales en 1952 y 53" (CORTÁZAR, 1987: 13).

${ }^{9}$ A propósito do assassinato do jovem judeu no conto, diz Mariano Ben Plotkin: "Indudablemente, la muerte gratuita de un judío narrada ficcionalmente en el año de 1947 era un tema de enorme densidad. Por entonces el mundo comenzaba a conocer en detalle los horrores de la Alemania nazi y sus aliados. No es casual que Borges y Bioy utilizaran este tema para asociarlo al peronismo" (PLOTKIN, 2005: 942-946).
} 


\section{2) Nós versus eles: intelectuais, massas e racismo}

Retrato negativo das práticas ritualísticas peronistas, o comício também simboliza o encontro do grupo de protagonistas com as massas apoiadoras do governo, constituindose numa espécie de "local primordial" do peronismo, para usarmos a terminologia criada por Marshall Berman em seu clássico livro Tudo que é sólido desmancha no ar. Para o autor estadunidense, locais como o bulevar parisiense de Baudelaire, em "Os olhos dos pobres", e o Projeto Nevski, do homem do subterrâneo de Dostoievski, se tornam espaços paradigmáticos na medida em que possibilitam intensos confrontos entre classes sociais distintas e expressam "as possibilidades e ciladas fundamentais, os encantos e impasses da vida moderna" (BERMAN, 2007: 268). Da mesma forma, a Plaza de Mayo de El examen adquire contornos similares por proporcionar um encontro igualmente revelador das tensões e impasses internos à cidade de Buenos Aires sob o regime de Perón, e que se fazem presentes em outros episódios da narrativa.

Com exceção feita a Stella, os protagonistas do romance podem ser definidos como pertencentes às classes médias e altas da sociedade portenha que reagiram com horror à entrada das massas peronistas na política e na capital do país. A personagem Clara, por exemplo, recorda ter sido criada em um ambiente típico da aristocracia criolla, no qual sua família, reunida em serões realizados na sala de seu tio Roque, ouvia anedotas do tempo do general Mansilla, militar participante das guerras civis argentinas e escritor do clássico Una excursión a los indios ranqueles. Sendo assim, tanto ela quanto os outros protagonistas veem com crescente ansiedade a repentina tomada dos seus espaços de convivência cultural, como o Teatro Colón, a livraria El Ateneo, os cafés, a Plaza de Mayo, entre outros. E, em duas ocasiões, Juan sintetiza esta sensação com a imagem dos "romanos viendo entrar a los bárbaros", impotentes frente à tomada de sua cidade (CORTÁZAR, 1987: 162).

Em sua maioria, essa sensação de invasão é sentida pelos personagens menos sob a chave de uma manifestação física do que como uma agressão - para usarmos as palavras de David Viñas - ao seu gosto refinado. ${ }^{10}$ Assim, no comício citado, um dos elementos que mais os incomoda é a transmissão da música erudita de Bach em meio às

\footnotetext{
10 Sobre o que diz David Viñas sobre a representação do peronismo na obra de Cortázar, ver o seguinte trecho: "De ahí que la presencia inquietante de las masas - los concretos, locales y numerosos 'cabecitas negras' - sean percibidas como esa posible 'agresión’ que acecha permanentemente en los zaguanes, tras los biombos o en las trasposiciones zoológicas que corroen las 'casas tomadas"” (VIÑAS, 1974: 119).
} 
manifestações da multidão e, principalmente, a distorção nela causada pela transmissão por alto-falantes. ${ }^{11}$ Em sua comparação do personagem Hardoy, do conto "Las puertas del cielo", com o narrador de "El matadero", de Esteban Echeverría, o escritor argentino Carlos Gamerro levanta um interessante ponto sobre o confronto estético entre os protagonistas de Cortázar e as massas peronistas:

Si vamos a buscar continuidades entre el joven unitario y Hardoy, habría que hacerlo en la mirada fascinada de sus autores sobre estos otros que amenazan destruirlos - físicamente, en Echeverría; metafísicamente, en Cortázar -; la identidad, en la obra de Cortázar, se construye fundamentalmente desde el gusto, y Hardoy se siente tan violado por el mal gusto de sus monstruos que el joven unitario por la mazorca de los suyos (GAMERRO, 2015: 174).

Se a identidade dos personagens de Cortázar é fundamentalmente construída sobre as bases do gosto, podemos entender certas atitudes tomadas pelos protagonistas de $E l$ examen, que sem esse elemento seriam vistas apenas como formas de pedantismo intelectual, como maneiras de resistirem a este outro avassalador. Assim, a recusa do cronista em impedir a escolha por uma música folclórica no jukebox do bar, a obstinação de Juan em ler seus poemas para um público não familiarizado com as vanguardas, a decisão do senhor Funes, pai de Clara, em comparecer a um concerto no meio da catástrofe, a recusa de Andrés em não abandonar as citações estrangeiras em conversas com aqueles que não as entendem: todas são formas de resistência de uma identidade coletiva contra a desagregação trazida pelas massas provincianas e sua manipulação pelo Estado peronista. ${ }^{12}$

Em outro artigo sobre Cortázar, Gamerro vê no grupo de El examen a primeira manifestação da seguinte dualidade ideológica que, segundo ele, marcará todos os romances posteriores do autor:

[O grupo de protagonistas] siempre se constituye como un 'nosotros' que incluye necesariamente el lector, y el imprescindible antagonista como un

\footnotetext{
11 “De lejos venía una música metálica, esa abyección de la música (cualquier música) cuando la echan desde los parlantes en serie, la degradación de algo hermoso, Antínoo atado a un carro de basura, o una alondra en un zapato" (CORTÁZAR, 1987: 60).

12 Sobre a apropriação peronista do folclore das províncias e sua imposição como música oficial da identidade argentina, diz Carolina Orloff: "Como parte del intento de Perón de llevar a cabo un proyecto 'nacional y popular' en lugar de un proyecto oligarca, en 1947 se aprobó la 'Ley del 50 por ciento'. Esta Ley especificaba que el $50 \%$ de la música que se emitiera en la radio nacional tenía que ser de origen argentino. Así, el tango y el folklore, ritmos como el chamamé, la chacarera, la zamba y el gato, fueron puestos al centro de la escena musical nacional" (ORLOFF, 2015: 1008-1014).
} 
'ellos' del cual este debe excluirse. [...] Cortázar funda un club exclusivo basado en una estética del consumo bastante arbitraria, pero que sigue, o más bien va definiendo, los vaivenes de esta esquiva categoría estético-existencial conocida como lo cool. (GAMERRO, 2010: 1207, grifo nosso).

Em El examen, este grupo se funda sob as características aglutinadoras da música erudita, das vanguardas surrealistas e cubistas, do existencialismo francês e do romantismo inglês, e tem como oponente aquele constituído pela valoração do folclore das províncias, da literatura popular, dos jornais sensacionalistas e, apesar de visto com alguma simpatia pelo cronista, do tango. Carlos Gamerro aponta para o elemento eminentemente classista desta oposição na literatura do primeiro Cortázar, na qual "esta matriz se constituyó primeramente como oposición social, de clase, y que la irrupción del peronismo fue, si no su causa originaria [...], su primer 'llenado' concreto" (GAMERRO, 2010: 1213).

Após termos definido a composição social do grupo de protagonistas como se originando nas camadas médias e cultas da população portenha, cabe-nos perguntar sobre a identidade deste outro social tão combatido e como ela se formula no texto do romance. Acreditamos que o seguinte diálogo entre o cronista, Juan e Andrés, acontecida a caminho do comício na Plaza de Mayo, nos parece crucial para começarmos a formular uma resposta a essa indagação:

- Todo Buenos Aires viene a ver el hueso - dijo -. Anoche llegó un tren de Tucumán con mil quinientos obreros. Hay baile popular delante de la Municipalidad. [...]

$-¿$ Vos estuviste? - dijo Juan.

- Profesionalmente - dijo el cronista -. Me mandé una nota padre.

Ergo fuiste el que consagró la peregrinación. No me mirés de reojo, porque es la verdad. Ellos pusieron la lona y tu diario trae la gente, a veinte guitas por engrupido.

- No hablés así - dijo Andrés, muy serio -. La gente no viene sólo por el diario. Ninguna campaña publicitaria puede explicar ciertos furores y ciertos entusiasmos. Me han dicho que los rituales son espontáneos, que a cada rato se inventan nuevos (CORTÁZAR, 1987: 60-61).

A partir deste trecho, é possível observar três pontos fundamentais no modo como as massas peronistas se compõem no romance. Em primeiro lugar, há a ênfase no seu 
caráter popular, em franca oposição ao dos protagonistas, que veem suas manifestações culturais de modo distanciado e irônico. Juntamente com esta, há, pela menção a Tucumán como lugar de origem de parte significativa da audiência, a relação das massas com as províncias do interior argentino. Ela volta a se repetir na já citada cantilena em honra da mulher de branco, cujas múltiplas origens - "Ella viene de..." - são todas menções a locais pertencentes às províncias. Como mostra Adrián Gorelik, a onda de migrações internas que se inicia com o processo de industrialização da década de 30 mudou o rosto dos trabalhadores da capital, cuja maioria deixa de ser composta por imigrantes europeus e passa a ter sua origem nas províncias pobres do país. Estes, por sua vez, permanecem marginalizados no que se constitui como a Gran Buenos Aires até que adentram a arena política sob a liderança de Perón. ${ }^{13}$ Para Gamerro, esta súbita aparição do interior foi vivenciada pelas camadas intelectuais das zonas centrais da capital como a revelação de "um outro país" interno à Argentina. ${ }^{14}$

Finalmente, o último ponto a ser tratado pelo trecho se dá na discussão entre Andrés e Juan sobre a participação do jornal do cronista na mobilização das massas para o comício, que reproduz um longo debate acerca de sua composição e do nível de sua espontaneidade durante o 17 de Outubro. Enquanto Juan reproduz argumentos próximos aos utilizados pelos antiperonistas, que definiam a presença das massas como formada pelo contingente de um lumpen-proletariado manipulado pela figura carismática do líder e pela propaganda dos meios de comunicação, Andrés parece se aproximar, sem que com isso abandone sua ferrenha oposição ao regime, da concepção oficialista do evento, que exalta o caráter espontâneo da participação das massas, tomadas como "el "verdadero pueblo' que encarnaba a la ‘verdadera nación”” (PLOTKIN, 2005: 830-839). Porém, mais do que se aproximar de alguma versão dos fatos, a posição deste personagem parece ser a de alguém que, ao contrário daqueles que, como Juan, buscam diminuir a força do

\footnotetext{
${ }^{13}$ Sobre o caráter peculiar tomado pela Gran Buenos Aires durante sua formação, prossegue Gorelik: "al revés que en las grandes ciudades del mundo, donde de ese modo se designaba el conjunto metropolitano, en Buenos Aires el término sirvió para designar exclusivamente los distritos 'externos' a la ciudad, separados del núcleo que les había dado origen. [...] Así se comprende, también, que 'la ciudad' pudiera producir esa escena primaria de la sorpresa y el descubrimiento cuando aquella realidad ignorada irrumpiera: la movilización del 17 de octubre de 1945, con su invasión de multitudes extrañas que llegaran hasta el corazón de la ciudad desde sus 'afueras' [...], para darle el bautismo popular al peronismo" (GORELIK, 2004: 93-94).

${ }^{14}$ Gamerro cita um trecho de ¿Qué es esto?, de Ezequiel Martínez Estrada, no qual se reproduz o espanto portenho frente às massas peronistas, assim como a sensação de invasão bárbara da qual fala o personagem Juan, de maneira exemplar: "Perón nos reveló no al pueblo sino a una zona del pueblo que, efectivamente, nos parecía extraño y extranjero. El 17 de octubre volcó a las calles un sedimento social que nadie había reconocido. Parecía una invasión de gentes de otro país hablando otro idioma, vistiendo trajes exóticos, y sin embargo, eran nuestros hermanos harapientos [...]" (GAMERRO, 2015: 170).
} 
peronismo ao enfatizar sua suposta falsidade, procura encarar o fenômeno de frente, a fim de compreendê-lo. Para Gamerro, tal é a atitude do próprio Cortázar em contos como "La banda":

Para Borges [no texto 'L'illusion comique'] lo que parecía real se revela falso, teatral, simulacro: la función llega a su fin el 16 de septiembre de 1955, el peronismo es una pesadilla de la que podemos despertar. En Cortázar, lo que parecía falso (el peronismo) se revela como verdadero, y lo que parecía verdadero (la Argentina como país civilizado donde la gente concurre al cine para ver películas de Anatole Litvak) es una tenue ilusión apabullada por el bolinche de la Banda de Alpargatas. La pesadilla no termina, sigue en la vigilia, no tiene límites (GAMERRO, 2010: 1156, grifo nosso).

Com tal atitude, Cortázar rompe com a pretensa imagem europeia de Buenos Aires e, ao colocar-se no extremo oposto, enfatiza o que considera como a mediocridade da intelectualidade argentina, incapaz de se opor ao avanço bárbaro do peronismo, que, ao contrário do que gostariam de admitir os intelectuais da época, se apresenta como a verdadeira realidade do país. ${ }^{15}$ Assim, o peronismo deixa de ser um pesadelo passageiro para se constituir como a verdadeira natureza do drama argentino, um pesadelo do qual é impossível despertar. No romance, Juan é aquele que encarna esse descontentamento de maneira mais dramática e, como podemos ver no seguinte trecho, seu repúdio visceral ao estado deplorável que julga encontrar no país faz com que ele ultrapasse certos limites e avance no tenebroso terreno do racismo:

- No me importan ellos - dijo Juan -. Me importan mis roces con ellos. Me importa que un tarado que por ser un tarado es mi jefe en la oficina, se meta los dedos en el chaleco y diga que a Picasso habría que caparlo. [...]

Me jode no poder convivir, entendés. No-poder-con-vivir. Y esto ya no es un asunto de cultura intelectual, de si Braque o Matisse o los doce tonos o los genes o la archimedusa. Esto es cosa de la piel y de la sangre. Te voy a decir

\footnotetext{
${ }^{15}$ Para Adrián Gorelik, a ascensão do peronismo com o episodio de 17 de Outubro evidencia o fracasso da imagem europeia de Buenos Aires, pois "permite entrever tan temprano como en la década de 1950, es decir, cuando la representación de ciudad europea recién parecía asegurarse, su primera crisis de confianza. Aquellos rasgos urbanos, la homogeneidad del espacio público y la marca expandida del centro, van a seguir funcionando durante mucho tiempo todavía. Pero la escena primaria de la 'casa tomada' muestra que, si esta figura de la Buenos Aires europea se ha completado, ha sido apenas para entrar en crisis" (GORELIK, 2004: 94).
} 
una cosa horrible, cronista. Te voy a decir que cada vez que veo un pelo negro lacio, unos ojos alargados, una piel oscura, una tonada provinciana,me da asco (CORTÁZAR, 1987: 110).

Longe de constituir um episódio isolado no romance, o recurso à ofensa racial na fala indignada de Juan apenas explicita um hábito recorrente no modo como os personagens identificam este outro social, de composição popular, provinciana e peronista. Diversas são as maneiras sob as quais ele é designado: para o cronista, é "ese negro de ojos sucios", "estas negras cotudas" ou "un negro besando a un chico como de catorce años"; Clara se assusta "porque el negro silbaba uno tras otro los temas de Petrushka"; e, finalmente, também o narrador se utiliza de termos como "del negrito vendiendo boletines" e "el peine en manos de un morocho pesado" (CORTÁZAR, 1987: 43, 66, 99, 194, 187 e 175).

Para Carlos Gamerro (2015), a presença tão categórica de julgamentos raciais depreciativos no romance se mostra como um dos momentos mais verdadeiros de toda a literatura do país, pois escancara, o profundo racismo arraigado na sociedade argentina e no autor, como explicitado num posterior mea culpa - e que foi ratificado e perpetrado por diversos intelectuais. ${ }^{16}$ Juntamente com seus contos "La banda", "Las puertas del cielo", "Ómnibus" e o já mencionado "La fiesta del monstruo", de Borges e Bioy, o romance El examen entra naquele rol de textos literários antiperonistas que retratam as camadas populares favoráveis ao regime sob o signo da bestialidade. ${ }^{17}$ Para Francisco Castellanos, isto se evidencia na relação que o romance faz das multidões peronistas com a neblina e os fungos que progressivamente tomam conta da cidade, pois, mais do que uma metáfora para o crescente clima de sufocamento instaurado pelo regime, eles aparecem, segundo o autor, como sendo “provocados por la 'inmunda humedad' causada por el sudor de las masas populares” (GUERRA CASTELLANOS, 2000: 44).

\footnotetext{
${ }^{16}$ Em anos posteriores, o Cortázar apoiador da Revolução Cubana e próximo ao movimento Montoneros realiza uma autocrítica em relação à sua postura antiperonista durante seus anos argentinos e ao que define como reacionarismo do conto "Las puertas del cielo", sobre a qual diz Gamerro: "Lo revelador es que Cortázar asume, aquí, las culpas del personaje; perfectamente podría haber dicho: eso no lo digo yo, lo dice Hardoy, éste es un relato sobre el racismo de nuestras clases altas. Pero elige no hacerlo, se hace cargo. Admite: yo siento (sentía en esa época) lo mismo que mi personaje" (GAMERRO, 2015: 173).

${ }^{17}$ Sobre a maneira como os personagens do conto "La fiesta del monstruo" são descritos, diz Plotkin: "Pero además de tratarse de individuos moralmente abyectos, hay una evaluación estética. Todos son descriptos como feos, mal olientes, peor hablados y deformes. Esta 'estetización' de la política fue una de las características centrales en la caracterización que importantes sectores de la oposición hicieron del peronismo" (PLOTKIN, 2005: 931).
} 


\section{3) O pesadelo peronista: autoritarismo, perseguição e falseamento da} história

Segundo o cronista, a concentração das massas na Plaza de Mayo - seu "hábitat natural", para usarmos um termo próximo do vocabulário zoológico dos personagens constitui um ambiente no qual se torna impensável para aqueles de sua camada social se expressar livremente: "El orador estuvo muy bien. No dijo nada y lo vivaron. Era perfecto. Nosotros, los que deberíamos decir algo, aquí estamos, como ves, hablándonos bajito por miedo a que nos muelan a palos. El orador ensaya mucho mejor que nosotros" (CORTÁZAR, 1987: 72). Neste trecho, mais do que a indiferença das massas frente à "palavra esclarecida" dos intelectuais, o que causa o temor e a indignação do personagem é a sua hostilidade contra o grupo ao qual pertence, o que, na Argentina peronista, ganha voz no famoso slogan do governo “¡Alpargatas sí, libros no!”. ${ }^{18}$

Como mostra o historiador Tulio Halperín Donghi, a hostilidade do regime peronista em relação ao intelectualismo logo toma forma nas medidas oficiais de intervenção nos jornais, rádios, escolas e universidades de todo o país. ${ }^{19}$ No romance, elas aparecem nas menções às mensagens propagandísticas feitas pelo jornal no qual trabalha o cronista e na definição de um ambiente no qual as mentiras se mostram como sendo mais aceitas que as verdades, "con lo cual los comunicados del gobierno alcanzan un éxito prodigioso" (CORTÁZAR, 1987: 157). Além disto, é no ambiente constituído pela Casa que os efeitos das políticas intervencionistas do Estado peronista se tornam mais

\footnotetext{
18 “A relação entre os livros (símbolo da cultura e dos intelectuais) e as alpargatas (calçado tradicional dos trabalhadores) para demonstrar a adesão ou a rejeição do peronismo, surgiu em 1945, quando o deputado socialista Américo Ghioldi criticou o então coronel Perón por promover as alpercatas em detrimento dos livros. Daí por diante, esses elementos transformaram numa palavra de ordem que incitava as manifestações pró-peronistas: 'Alpargatas sí! Libros no!' A censura de Jauretche [em seu livro Los profetas del ódio] à intelligentsia reflete bem o forte antiintelectualismo que desde o começo impregnou as manifestações de apoio a Perón, inclusive as do 17 de outubro de 1945, e a maneira como esse antiintelectualismo paradoxalmente se transformou em conteúdo da própria identidade dos intelectuais peronistas" (NEIBURG, 1997: 52, grifo do autor).

${ }^{19}$ Para Halperín Donghi, é a prática de tais intervenções que faz o regime peronista ser qualificado de, mesmo quando preserva certa aparência democrática, uma "semi-ditadura": "[...] la labor de la Secretaría de Prensa, bien pronto identificada con la de su jefe, el señor Apold, contribuyó a dar al periodismo argentino un tono de pétrea uniformidad, apenas rota por los escasos órganos independientes, que sabían demasiado bien que sólo sobrevivirían gracias a su prudencia, y cultivaban con ahínco esa salvadora virtud. De la misma manera utilizó el gobierno todos los medios de proselitismo que la máquina estatal le ofrecía, y en primer término los de la enseñanza. En la Universidad, depurada tras de la expulsión de miles de docentes desafectos [...], reinó también un conformismo gris. En la enseñanza secundaria y la primaria la acción fue más decidida: el rostro angélico de la señora Eva Perón comenzó a mostrarse, envuelto en nubes delicadamente rosadas, a la devoción de las promociones infantiles, en las viñetas de los libros de lectura" (HALPERÍN DONGHI, 1995: 158).
} 
evidentes. Espaço pelo qual se faz uma alegoria da abertura peronista do ensino superior a toda sociedade e da doutrinação imposta pelo regime à educação, é também nela que se dá um dos episódios mais dramáticos de todo o romance: o impedimento da entrada no prédio pelos inspetores e o brusco cancelamento da prova à qual os protagonistas devem comparecer e em cuja véspera se passa a quase totalidade da narrativa.

Nesse episódio em específico, acompanhamos a chegada dos protagonistas, que, após percorrer uma cidade em acelerado processo de desintegração, dominada cada vez mais pela ação dos fungos e da neblina, encontram os portões de la Casa impedidos por dois inspetores que se recusam a abri-lo, numa clara alusão à extinção do livre acesso à instituição. Depois de uma longa e tensa espera, marcada pelas entrevisões de movimentos escusos no interior do prédio e pelo progressivo apagar de suas luzes, numa evidente metáfora da extinção da razão, o decano começa, juntamente com os inspetores, a distribuir diplomas a todos os presentes, inclusive ao cronista que, não sendo aluno, se regozija ironicamente da situação. ${ }^{20}$ Já Stella se assombra com a atitude de Andrés, Juan e Clara, que, sem esperar seu turno, abandonam o prédio numa recusa a aceitar tamanha farsa. Também o vigia, que não lhes impede a saída, se surpreende ao vê-los recusar os diplomas: "y les miraba las manos, los bolsillos, verdaderamente un poco asombrado de verlos irse así con las manos vacías" (CORTÁZAR, 1987: 251).

Antes de sair, porém, os personagens olham uma última vez para dentro do decanato e se deparam com a visão do retrato de San Martín pendurado entre os móveis. Para Carolina Orloff, cada aparição da figura do prócer argentino no romance tem a função de colocar em relevo sua importância para a história do país e, principalmente, a apropriação que dele realiza o peronismo (ORLOFF, 2015: 747). ${ }^{21}$ Desta forma, a presença do rosto de San Martín enfatiza a cooptação de seu símbolo por aqueles que interditaram a escola e se relaciona de maneira imediata com a cena um pouco anterior da mudança de quadros. Nela, Andrés e Clara andam pelos corredores não bloqueados da Casa e, ao ver dois indivíduos retirando alguns quadros da parede, realizam o seguinte diálogo:

\footnotetext{
20 “"Me agarro uno', pensó el cronista, retorciéndose. 'Me lo cuelgo en el escritorio, me lo llevo a la redacción"” (CORTÁZAR, 1987: 251).

${ }^{21}$ Segundo Mariano Ben Plotkin, a ideologia peronista se constituiu como um amálgama de diferentes "mitos de origem", recuperados e ressignificados mediante uma "apropiación selectiva de elementos del pasado más o menos remoto; en otras palabras, ¿Perón era como San Martín o como Rosas?, y en todo caso, de ser identificado con este último ¿tenía esta asociación una valencia positiva o negativa?; además, el 17 de Octubre ¿compartía su naturaleza con el 25 de Mayo o con la invasión de los caudillos 'bárbaros' a la ciudad de Buenos Aires en 1820" (PLOTKIN, 2005: 76)?
} 
- Mudanza - dijo Clara-. Qué idiotas.

- No, no se mudan. Quieren mudar a los demás. Empiezan con los más indefensos.

- ¿De quién hablás? - dijo Clara, mirándolo.

- Creo que de nosotros - dijo Andrés -. De los retratos colgados en las paredes. Una vez pensé en lo que sentiría una música hermosa si le fuera dada una conciencia. No es imposible pensarlo, ¿verdad?

$[\ldots]$

- [...] ¿Y qué ocurriría si la música tuviera conciencia?

- Nada, se me dio por imaginar el horror de una música bella que se siente vivida por una boca indigna, silbada por un mediocre cualquiera [...]. Y lo pensé al darme cuenta[,] lo vengo viendo desde hace tanto, pero hoy —al sentir cómo los valores, esos retratos si querés, están inermes en las manos de los tipos que los apilan en un rincón. Que ni siquiera los destruyen; simplemente los arrumban.

- Nadie se deja arrumbar si no es arrumbable - dijo Clara, divirtiéndose en hacer rodar las erres -. Eso es lo horrible (CORTÁZAR, 1987: 234, grifo nosso).

Neste diálogo se dá, de maneira exemplar, a explicitação de uma luta política pela memória, na qual peronistas e antiperonistas se apropriavam dos símbolos da história nacional argentina na criação de suas próprias tradições. Enquanto os últimos se identificavam com uma tradição de cunho liberal, unitária e republicana, aqueles recuperavam as figuras dos caudillos federalistas, numa reencenação da luta das províncias excluídas contra o centralismo portenho, visto como elitista e entreguista. ${ }^{22}$ Com a vitória dos primeiros nas eleições de 1946, foi a sua tradição a alçada pela máquina propagandística do governo ao lugar de ideologia oficial da nação, difundindo, com seus alto-falantes, versos como "y los montoneros ataron sus caballos a la pirámide", ouvidos

\footnotetext{
${ }^{22} \mathrm{Um}$ dos principais nomes do revisionismo histórico, Arturo Jauretche, identificava a massa peronista como participante de uma espécie de "movimento pendular" ao longo de toda a história argentina: "Estas multitudes (definidas como 'el verdadero pueblo') eran protagonistas de la historia nacional ubicadas al mismo tiempo por fuera de la historia, ya que la encarnaban de manera diferente aunque conservando su identidad esencial que era inmutable. Estas masas habían hecho su aparición en forma de las 'montoneras' del siglo XIX en su lucha contra el centralismo porteño. Luego de la derrota de los caudillos por la capital, la multitud volvió a aparecer en el siglo XX, pero ahora como votantes bajo el imperio de la Ley de Sufragio Universal de 1912, que otorgaron el triunfo a un nuevo 'caudillo popular': Hipólito Yrigoyen. El golpe del 30 y la 'década infame' constituyeron otra instancia de derrota y exclusión de las multitudes que volvieron a aparecer el 17 de Octubre en la forma de 'obreros nuevos', inmigrantes recientes del interior" (PLOTKIN, 2005: 890-896).
} 
pelos personagens na Plaza de Mayo (CORTÁZAR, 1987: 68). Esta, por sua vez, participa ativamente nesta disputa simbólica pelo passado, pois, se antes vinculada à tradição liberal, principalmente por sua origem na Revolución de Mayo de 1810, tem seu espaço ressignificado e transformado, tornando-se um lugar de memória peronista, para usar o termo do historiador Pierre Nora. ${ }^{23}$

Pertencentes ao grupo derrotado, os personagens de El examen possuem a sensação de se viver numa história falsificada e, por isso, olham para o passado com uma visão impregnada de nostalgia, associando-o com o tempo de sua juventude, quando ainda eram estudantes e não haviam passado pelas mudanças que iriam transformar seu modo de viver (ORLOFF, 2015: 659). Desta forma, a melancolia acaba se tornando o estado de espírito dos protagonistas, com a exceção de Stella, que não parece se incomodar com a atual situação, e, como define Patrick O'Connor, é esta nostalgia pelo passado que, misturada com o descontentamento do presente e a desesperança perante o futuro sob o governo de Perón, define o tom de todo o romance (ORLOFF, 2015: 818-826).

Para além das violências ideológicas, existem outros motivos - pode-se dizer mais “concretos" - para o descontentamento melancólico dos protagonistas. Desolados após presenciar a farsa dos diplomas, eles decidem entrar num café próximo à faculdade e lá encontram um de seus professores, ao qual pressionam a fim de fazê-lo revelar o motivo de sua ausência durante o exame cancelado. Depois de muita insistência, o professor se mostra nervoso e lhes responde que não havia outra saída, dando a entender a existência de uma ameaça para os funcionários que tentassem ir contra o cancelamento. Imediatamente, Andrés se lembra do episódio da morte de um escritor dentro da livraria El Ateneo - “"Muerto', pensó Andrés” (CORTÁZAR, 1987: 255) - e faz com que o leitor recupere a angustiada reflexão feita pelo personagem no calor do acontecimento:

Se sentía irritado, seguía viendo esa cara tan blanca y sin relieve, de pómulos salientes, mentón débil y sienes hundidas. 'Escapista', pensó, colérico. 'Entre la niebla y las Ochenta Mujeres, escapista. Cobarde'. Y la ternura lo ganaba. Ahora veía mejor la flaca figura en los pasillos del Odeón, se acordaba de un choque involuntario y un cambio de excusas, frente a la boletería de un cine.

\footnotetext{
23 "Es que la Plaza de Mayo ha ocupado en la tradición histórica argentina un lugar particular, convirtiéndose en lo que el historiador francés Pierre Nora ha llamado 'un lugar de memoria', es decir un espacio construido históricamente en el que se cristaliza la memoria colectiva, pero cuyo referente es él mismo. En este sentido, puede decirse que la Plaza de Mayo ya era un lugar de memoria en la tradición histórica argentina. Más adelante, Perón la convertiría en un lugar de memoria peronista" (PLOTKIN, 2005: 646-652).
} 
Siempre solo, o hablando con amigos pero solo. ¿Quién era? Pensó si habría dejado un libro, alguna música. Sonriendo, dolido, se reprochó esa necesidad de calificación. Todo lo que podía decir, todo lo que valía, era la frase de Marlow al hablar de Lord Jim: He was one of us. Y no ayudaba mucho, realmente (CORTÁZAR, 1987: 211).

Para além de qualquer nível de uma verdadeira convivência entre Andrés e o escritor, o que faz com que o personagem lamente profundamente a morte deste último é o fato de vê-lo como um igual, de reconhecer na sua tragédia o símbolo do destino comum de todos os intelectuais sob o regime peronista. ${ }^{24}$ Este, por sua vez, é pintado com tons tão sombrios que até a morte parece ser preferível, como se fosse uma fácil e covarde solução. Não à toa, Ricardo Piglia define a representação que El examen realiza da vida política na Argentina sob o governo peronista como sendo uma retomada, em todo o seu esplendor, da concepção da história como pesadelo, já presente em Camus e Onetti (PIGLIA, 2001: 49). Assim, há novamente a ideia da Argentina peronista como um pesadelo real, duradouro e inescapável, cujo despertar se associa, agora, com a fuga escapista da morte.

Com o desfecho do romance, as ameaças fantásticas e as reais se misturam e o aumento no ritmo da desintegração de Buenos Aires pelos fungos é concomitante com a multiplicação da violência e da vigilância do aparelho de Estado. Desta forma, não só a intervenção na Casa perturba os protagonistas, como o assassinato de um cachorro por um guarda no metrô e a repetida aparição de carros de patrulha em suas proximidades evidenciam o acirramento de um círculo cada vez menor. ${ }^{25}$ Obcecado pelo temor em seguir o mesmo destino do companheiro morto e pelo diagnóstico da ineficácia das ideias num regime que as neutralizou e cooptou por completo, Andrés decide levar uma pistola no bolso do seu casaco, realizando a passagem, que será tão comum nas décadas de 60 e 70 , da resistência intelectual para a luta armada. ${ }^{26}$

A alegoria ganha cada vez tons mais sinistros e Francisco Castellanos identifica, na neblina e nos fungos destruidores, algo de natureza "un poco similar a la amenaza fantasmal de "Casa tomada"” (GUERRA CASTELLANOS, 2000: 47). Ao recuperar a

\footnotetext{
${ }^{24}$ Após o discurso de ódio racial de Juan contra os provincianos, Clara lhe pergunta se também sente asco de seus amigos intelectuais. Sua resposta é categórica: "No - dijo Juan -. Porque los que son como nosotros me dan lástima" (CORTÁZAR, 1987: 110).

25 "Lo que creían un taxi era un coche negro con chapa oficial, lleno de policías custodiando a alguien que no pudieron ver (CORTÁZAR, 1987: 224)."

26 "Me parece tan absurdo - dijo Clara -. En tus bolsillos no me imagino más que libros y tabaco" (CORTÁZAR, 1987: 239).
} 
leitura consagrada que vê neste conto, de atmosfera próxima à de um pesadelo, uma alegoria da invasão peronista sobre os espaços particulares da classe média portenha, o crítico o aproxima do romance, como se aquele fosse uma espécie de ensaio, de conteúdo ainda muito alusivo e um pouco incerto, sobre o uso literário da alegoria política e que apenas se concretizará no texto de El examen. ${ }^{27}$ De maneira semelhante, Gamerro diz que Cortázar constrói o peronismo como "lo otro por antonomasia", ou seja, como uma ameaça "que no se puede decirse, [e que] por eso [...] se manifiesta únicamente como ruidos imprecisos y sordos, susurros ahogados" (GAMERRO, 2010: 1239-1246).

Intervenções na cultura e na educação, perseguições policiais e assassinatos políticos ocorrem num espaço em constante desagregação e progressivamente dominado pela misteriosa neblina, proliferadora dos fungos que corroem a estrutura física da cidade e consequentemente limitam o espaço de movimentação dos personagens. Tudo - desde o que se pode ser dito até o que não se pode -, ao final da narrativa, conflui para a criação de um clima de pesadelo, cujo fim não é visível aos protagonistas. Frente a tamanha desolação, dois são os caminhos por eles escolhidos, os únicos que o romance possibilita além da aceitação passiva do horror. Enquanto Juan e Clara fogem de barco e realizam o que Gamerro define como "el mítico cruce del río a Uruguay", pelo qual "la literatura antiperonista entronca con la tradición antirrosista", Andrés escolhe a luta armada e fica para morrer nas mãos de um perseguidor misterioso e implacável. ${ }^{28} \mathrm{Na}$ alegoria da história como pesadelo tecida pelo texto de El examen, a ação transformadora é esvaziada de eficácia e apenas duas são as maneiras de despertar: o exílio ou a morte.

\footnotetext{
${ }^{27}$ Sobre a recorrência desta interpretação na leitura não só do conto - com a qual Cortázar não concordava, pois dizia tê-lo escrito justamente a partir de um sonho - como de toda a produção literária do chamado "primeiro Cortázar", diz Gamerro: "Es habitual comenzar la serie con la lectura de 'Casa tomada' realizada por Juan José Sebreli en Buenos Aires, vida cotidiana y alienación: 'Un cuento de Julio Cortázar, 'Casa tomada', expresa fantásticamente esta angustiosa sensación de invasión que el cabecita negra provoca en la clase media'. Apenas una oración, y veintitrés palabras, han bastado para constituir la 'hipótesis Sebreli', a partir de, o contra la cual, han girado desde entonces todas las hipótesis sobre la viabilidad, o no, de leer en clave peronista los cuentos del primer Cortázar (GAMERRO, 2010: 973-8)". Porém, esta interpretação política não é a única, mas uma entre diversas leituras possíveis, como nos mostra o crítico Andrés Avellaneda em seu clássico livro El habla de la ideología: modos de réplica literaria en la Argentina contemporánea" (AVELLANEDA, 2014: 113).

${ }^{28}$ O exílio no país vizinho foi o destino de muitos dos principais intelectuais opositores a Rosas, como Juan Bautista Alberdi, Esteban Echeverría e Juan María Gutiérrez (GAMERRO, 2010: 1175). Sobre o caminho da aceitação passiva do regime, apenas Stella, personagem mais próxima às camadas populares, e o cronista, símbolo da cooptação dos meios de comunicação pelo Estado, optam por permanecer no estado atual.
} 


\section{Fontes}

CORTÁZAR, Julio (1987 [1986]). El examen. Madrid: Alfaguara.

\section{Referências bibliográficas}

AVELLANEDA, Andrés (2014). El habla de la ideología: modos de réplica literaria en la Argentina contemporánea. Buenos Aires: Editorial Eudeba.

AVELAR, Idelber (2003). Alegorias da derrota: a ficção pós-ditatorial e o trabalho do luto na América Latina. Belo Horizonte: Editora UFMG.

BERMAN, Marshall (2007). Tudo o que é sólido desmancha no ar: a aventura da modernidade. Trad. Carlos Felipe Moisés e Ana Maria L. Ioriatti. São Paulo: Companhia das Letras.

DULITZKY, Alejandro (2010). El escritor desclasado: Julio Cortázar y la sociedad argentina del peronismo clásico. Revista Pensar. Epistemología y Ciencias Sociales. Rosario, no. 5, pp. 29-37.

FORASTELLI, Fabricio (2012). "Pobre pibe", "lindo pibe". Notas sobre peronismo y estilística a partir de "Torito" de Julio Cortázar (1954). Revista del Ciffyh Área Letras. Córdoba, no. 3, pp. 1-18.

GARCÍA MARTÍN, Luis (1987). El examen: La prehistoria de Julio Cortázar. Cuadernos Hispanoamericanos. Madrid, n. 444, pp.153-156, jun.

GAMERRO, Andrés (2010). Ficciones barrocas: una lectura de Borges, Bioy Casares, Silvina Ocampo, Cortázar, Onetti y Felisberto Hernández. Buenos Aires: Ed. Eterna Cadencia, Kindle Edition. (2015). Facundo o Martín Fierro. Buenos Aires: Sudamericana, Kindle Edition.

GORELIK, Adrián (2004). Miradas sobre Buenos Aires: historia cultural y crítica urbana. Buenos Aires: Siglo Veintiuno.

GUERRA CASTELLANOS, Francisco Emilio de la (2000). Julio Cortázar, de literatura y revolución en América Latina. México: Unión de Universidades de América Latina.

HALPERÍN DONGHI, Tulio (1995). Argentina en el callejón. Buenos Aires: Ariel.

MONTES-BRADLEY, Eduardo (2014). Cortázar sin barba. Barcelona: Red Ediciones.

NEIBURG, Federico (1997). Os intelectuais e a invenção do peronismo. Trad. Vera Pereira. São Paulo: Edusp.

NORA, Pierre (1993). Entre memória e história: a problemática dos lugares. Projeto História. Revista do Programa de Estudos Pós-Graduados em História e do Departamento de História da PUC-SP. São Paulo, n. 10, pp. 7-28, dez.

ORLOFF, Carolina (2015). La construcción de lo político en Julio Cortázar. Buenos Aires: Ediciones Godot, Kindle Edition.

PIGLIA, Ricardo (2001). Sobre Cortázar. In: Anagrama, pp. 45-49. Crítica y ficción. Barcelona: Ed.

PLOTKIN, Mariano Ben (2005). El día que se inventó el peronismo. La construcción del 17 de Octubre. Buenos Aires: Sudamericana, Kindle Edition.

SARLO, Beatriz (2005). A paixão e a exceção: Borges, Eva Perón, Montoneros. Trad. Rosa Freire d'Aguiar. São Paulo: Companhia das Letras; Belo Horizonte: Editora UFMG. 
TERÁN, Oscar (2008). Historia de las ideas en la Argentina: diez lecciones iniciales, 1810-1980. México, D.F.: Siglo Veintiuno.

VIÑAS, David (1974). Literatura argentina y realidad política: de Sarmiento a Cortázar. Buenos Aires: Ediciones Siglo Veinte.

Artigo recebido em 06 de março de 2019.

Aprovado em 19 de maio de 2019.

DOI: 10.12957/intellectus.2019.40666 